\title{
Innovation dynamics in the biobased industry
}

\author{
Jose Vitor Bomtempo ${ }^{1 *}$ and Flávia Chaves Alves ${ }^{2}$
}

\begin{abstract}
This paper studies the biobased industry evolution as an innovation process, as this approach allows us to widen the current perspective of most literature in this field, by offering insights into the current mechanism as well as the future possibilities of this industry. This new industry, which is still in its infancy, conceals a number of interrelated alternatives in four key dimensions: raw materials, conversion technologies, products, and business models. Considering an emerging industry, the selection environment is complex and the competitive patterns are not yet established. Product and process innovations occur intensely without the existence of dominant designs or enabling technologies. Entry and exit barriers are low, with coexisting innovators from different knowledge backgrounds proposing several concepts and building diverse technological trajectories. In this context, Brazil seems to possess some comparative advantages due to its experience in first-generation ethanol production and related agricultural developments, as well as the successful experience with green polyethylene. Nonetheless, this country faces important challenges concerning the four key dimensions explored in this paper. As the biobased industry develops, government support and private initiatives need to align in order to move the country to a prominent position.

Keywords: Biobased industry; Renewable raw materials; Innovation; Brazil
\end{abstract}

\section{Introduction}

At the world level, the consumption of biofuel as a transport fuel is expected to grow $10 \%$ per year in the next decades. In the USA, the Renewable Fuel Standard requires that by 2022, biofuels used as a transport fuel increase to around 36 billion gallons from 13 billion gallons in 2010 [1]. On the other hand, biofuels have been a matter of debates and controversies in recent years. Land use and food competition have been the object of intense debate. As a result, many papers, studies, and reports on biofuels have been published. Apart from the technical and specialized ones, most publications deal with the social, economic, and environmental aspects of biofuel production and utilization. In general, these studies focus on a single aspect of the biofuel case. Studies taking into account how these aspects are interrelated and how they are evolving are scarce. To consider the biofuel case as an innovation process could create insights into the way we see the industry as a whole and offer a different vision of its future.

\footnotetext{
* Correspondence: vitor@eq.ufrj.br

${ }^{1}$ School of Chemistry/Institute of Economy/Universidade Federal do Rio de Janeiro (UFRJ), Technology Centre, Bloco E, room 209, Ilha do Fundão, Rio de Janeiro 21941-909, RJ, Brazil

Full list of author information is available at the end of the article
}

We argue that the perspective should be widened in order to take into account the very complex construction process of the future biobased industry. This new industry, which is still in its infancy, conceals a number of interrelated alternatives in raw materials, conversion technologies, and even new products and business models. It is likely to be very different from ethanol or biodiesel industries, which are the biofuels currently being produced. It should rather be seen as a new biomass-based industry including, apart from fuels, biobased chemicals and polymers. Opportunities in biobased chemicals and polymers are very promising $[2,3]$. By 2050, its potential substitution for high-volume chemicals has been estimated, under favorable conditions, at around $38 \%$ of the organic chemicals market [2].

This paper aims to explore the emergence of this new industry and its implications from an innovation dynamics point of view. Our exploratory analysis, based on fundamental concepts in innovation economics and management, particularly on technological trajectories and selection environment, technology life cycle, and innovation strategies, tries to elaborate on the nature of these changes and its consequences for the biobased industry. 
The paper is organized as follows: the next section provides a brief discussion of the theoretical background on innovation studies, placed in the context of the biobased industry. Innovation dynamics is described herein, based on the four key dimensions that we suggest as industry-structuring dimensions: raw materials, technologies, products, and business models. The last section presents the concluding remarks.

\section{Review \\ Innovation studies and the context of the biobased industry}

The ongoing construction of the biobased industry can be seen as an innovation process in which multiple alternatives arise and are tested by the competitors. Some of these alternatives tend to thrive while others may not meet the market approval and, as a result, tend to be abandoned. In this selection process, innovators try out new business models, introducing disruptive innovations [4] that can modify the established value chains, ease the entry of new competitors, and eventually give birth to a new industrial structure.

The process by which innovations are adopted can be studied from various perspectives. Two critical variables regarding the adoption of a particular innovation have been identified [5]: (i) the existence of well-defined performance criteria and (ii) the presence or absence of increasing returns of adoption. The adoption can be rationally oriented if a clear definition of performance is available. On the other hand, the adoption can be socially constructed if definitions of performance are not established, and thus, network effects tend to prevail.

The value proposition of biofuels and bioproducts has been changing and evolving over time, in parallel with research and development and commercial implementation. Environmental and sustainability issues have become more acute and are affecting the choice of raw materials - direct or indirect effects on land use, energy balance, and greenhouse gases evaluations have to be taken into account. The adoption process thus becomes increasingly difficult to predict and is subject to the influence of many factors rather than pure technical merit.

In order to respond to a social problem and/or explore a business opportunity, innovators have to deal with a particular selection environment. According to Dosi [6], the selection environment can be defined as the economic forces and social and institutional factors that act as selection mechanisms for technologies. The selection environment interpretation leads initially to multiple alternatives that can, in theory, respond to the referred problem. Nevertheless, a selection process takes place and most alternatives tend to be abandoned. There is a convergence over a few alternatives (in some situations, only one) which appear as the market winners. This process is usually designated as the search for a dominant design (DD), defined by Abernathy and Utterback [7] as the product or technology, in a certain class, that gets the market preference.

The innovation dynamics model proposed by Abernathy and Utterback [7] points out that the emergence of the DD is a critical stage in the consolidation and dissemination of a technological innovation. Until this point, multiple concepts are in place in a situation that is characterized by a high level of experimentation. This is called the fluid phase of innovation dynamics.

After the emergence of the DD, competitors focus on the development of more efficient production processes. The challenge then is to produce efficiently and at scale, configuring what has been called the transitory phase. An important aspect can be observed in the case of process industries. Process industry products, such as fuel, polymers, and other chemicals, differ from assembled products such as cars, electronics, and many consumer goods, in the nature of the DD. As the product concept is more clearly defined (e.g., biofuel specifications to be used in a particular type of engine) at the beginning of the innovation process, this definition is, in practice, a necessary condition for the product to be launched in the market. The uncertainty in this case lies mainly in the process. It is said that instead of a DD, which has mainly to do with the product definition, innovators search for an enabling technology, related to the process.

Aside from the technology itself, other factors can influence the emergence of the $\mathrm{DD}$, such as regulations and government initiatives, the presence of complementary assets, firms' strategic movements, and user-producer interactions, which are directly linked with the business models adopted.

Regulation acts and government initiatives can be decisive in the definition of the DD. A regulatory frame frequently imposes a standard - in the case of renewable fuels, regulations and policies are seen as a key factor in the development and diffusion of innovations [8].

A well-developed relationship between the innovator and the users can have significant weight in the innovating firm's power to influence the definition of the DD. In the fuel scenario, considering the current selection environment, the relationship would extend to the whole chain, ranging from the raw material suppliers to the regulatory organizations and the biofuel end user.

Firms' strategic movements can decisively contribute to the definition of the DD. Cooperative innovation strategies, licensing policies, and investment decisions, for example, can facilitate the definition of the DD. Investment decisions can favor a particular technological 
alternative and, as a consequence, improve its learning curve and generate positive externalities that will reinforce its adoption.

Complementary assets [9] refer to the resources needed, besides the central technological know-how, to successfully commercialize an innovation. Competitive manufacturing, access to distribution and marketing channels, after-sales and technical services, and complementary technologies and marketing are the most common complementary assets. Agents that hold specialized complementary assets marketing channels and well-developed relational skills with users, for example - can have a strong position in the competition for the DD. The complementary assets held by oil and gas companies can have a decisive influence in defining the DD and, as a result, contributes to maintaining their position as industry leaders despite major technological changes in fuels. A similar role can be attributed to the chemical industry concerning bioproducts and biopolymers or to the car industry for transportation innovations. In the biobased industry, specialized assets can also be found upstream in the production chain at the feedstock supply level. In this case, the agroindustry is better positioned than technology-based companies, such as startups or chemical/petrochemical companies. Other assets which may be critical in shaping the future biobased industry are the capabilities in process engineering. These capabilities, as a rule, are not available in the technologybased startups that lack experience in scale production and marketing.

It is also interesting to observe the diversity concerning functional sources of innovation [10] and technological trajectories due to sectorial patterns of innovation [11]. As will be discussed in the following subsection, structuring the biobased industry requires the organization of different stages of a production chain that, by their very nature, differ in these aspects and influence innovation dynamics.

As mentioned above, we propose the analysis of four different but interrelated key dimensions in order to understand innovation dynamics in the biobased industry.

\section{Raw materials}

The starting point for structuring a biobased industry is the organization of the raw material supply. This is a complex issue since it involves not only the logistical aspects [12] but also the efforts regarding agricultural technologies and biomass treatment for further conversion. From this perspective, innovation in the initial chain stage involves a wide range of knowledge domains.

Unlike the transition from a coal-based chemical industry to petrochemicals, where the availability of raw materials enabled the change [13], the biobased industry's evolution presents the challenge of finding/developing renewable raw materials that are suitable for economically feasible conversion technologies to bioproducts and biofuels.

It is possible to observe great efforts to develop agricultural crops, focused on improving/developing new varieties, as well as new equipment and machinery for seeding and harvesting, aiming at productivity gains and efficiency. New scientific knowledge, such as synthetic biology, appears to be crucial in order to reach new research and development goals.

It is important to highlight that there is great interest in developing the so-called second-generation sugar, which is derived from lignocellulosic materials such as agricultural and forest residues. In this approach, the treatment process to prepare a suitable feedstock for the conversion process becomes a technological challenge. Multiple alternatives have been proposed which depend on biomass composition and so will greatly vary according to raw material choices. Biochemical and thermochemical treatments are being tested, although there is no clear commercial or technical advantage of one over the other, yet $[14,15]$.

Brazil is well positioned in this field since sugarcane is currently accepted as the most suitable raw material for sugar fermentative processes, although improvements can and must continue to be made [16]. The availability of agricultural crops, intense solar radiation, abundance of water, diversity of climate, and being a pioneer in biofuel production on a large scale are factors that create great opportunities for Brazil in this context [17]. Nevertheless, there is a need to strengthen knowledge in new genetic modification methods as well as efforts to adopt suitable agricultural machines. The recently launched PAISS Agrícola [The Brazilian Development Bank (BNDES) - Funding of Studies and Projects (FINEP) Joint Support Plan for Agricultural Technological Innovation of the Sugarcane Industry] [18], which aims to foster development and pioneer production of agricultural technologies, as well as the adaptation of industrial systems for the sugarcane productive chain, highlights the importance of innovations related to the raw material. Increasing sugarcane productivity through different technologies is a crucial issue for the whole productive chain, and incentives from the government through its funding agencies are decisive in order to reaffirm Brazil's goal to be well positioned in the biobased industry.

\section{Technologies}

The second key dimension consists of conversion technologies, comprising a wide variety of technological approaches such as biochemical, thermochemical, and chemical routes. Beyond these, there are many propositions that combine different approaches, leading to increased diversity and greater knowledge bases. 
Research on conversion technologies for biobased products seems to consider a divergent approach [19], which means that the focus should be on technology development rather than a specific product. So, innovators concentrate on technology that can then be applied to arrive at feasible products. Identifying these products could be seen as a further stage in the process. On the other hand, biofuel research focuses on a target product, trying to find the most promising technology to produce it. In this case, a convergent approach is adopted.

This diversity has other implications. One important implication is that biochemical routes, through the use of engineered microorganisms, could change the current productive chain conception. Specifically for biobased products, the adoption of biochemical routes can lead to a great change in the way productive chains are organized, due to the possibility of direct conversion to products that, as per the current petrochemical approach, would need more reactive steps. So, a reduction on plant scale and capital cost could change innovation and competitive dynamics. This point illustrates how the biobased industry, in its structuring process, allows new concepts in very consolidated issues, such as scale economy in the chemical industry.

Within biochemical processes, microorganism selection or genetic modification and scaling-up are important technological challenges, receiving considerable attention. Chemical processes, on the other hand, need catalyst development in order to improve efficiency and selectivity. Thermochemical routes, as pyrolysis and gasification, are under development focusing on using heterogeneous raw materials, mainly urban solid waste and agriculture/forest residues. As long as these different routes can lead, in some cases, to the same product, the structuring process tends to induce some convergence with the emergence of an enabling technology. Nevertheless, this convergence can be limited if the structuring process favors complementarity among routes.

Brazil has considerable experience in first-generation ethanol production through sugarcane fermentation. In 2011, BNDES and FINEP launched the PAISS (BNDESFINEP Joint Plan to Support Industrial Technological Innovation in Sugarcane Sectors) to foster innovation in three main areas - second-generation ethanol, new products from sugarcane, and gasification [20] - which demonstrates that the referred agencies understand the importance of Brazil participating in the existing technology race. Thirty-five business plans from twenty-five firms were approved, and the program is considered a successful model for innovation funding, with many approved projects underway [20].

\section{Products}

The importance of product innovation has been increasing in recent years. Industry dynamics was initially driven by the production of ethanol and biodiesel. In this scenario of known products, innovation strategies were focused on processes. However, for three reasons, the interest in product innovations is growing. Firstly, there is an increasing search for drop in fuels [21]. Drop in fuels deliver a performance equal or close to that of conventional fuels (gasoline, diesel, or jet fuels). Thus, engine adaptation is not required and the existing transport and distribution infrastructure can be easily accessed. In this aspect, the available complementary assets could favor the drop in fuels instead of ethanol. Secondly, the interest in biobased chemicals instead of biofuels has been growing. Some projects are dedicated to the production of chemicals and polymers: existing chemicals using new biobased routes and new products not currently available in the petrochemical industry. The third factor is a combination of the two mentioned above. Product portfolio diversification allows for combining biofuels, which are high-volume and low-price products, with chemicals and specialties that tend to be lower-volume and higher-margin products. As a consequence, the importance of integrated biorefineries with multiple products has been increasing. These projects, compared to the dedicated production of biofuels, are still in the initial stages of development but are seen as key to the future of the biobased economy [22]. It must be remembered that product diversification can reinforce the environmental performance of the biobased industry as well [23].

Excluding conventional ethanol and biodiesel, it is possible to identify around 50 different products in different stages of development [24] and hundreds of different companies involved. Nevertheless, there remain an impressive number of open questions concerning the future of many of these products.

A current dilemma in the industry, particularly in the case of bioplastics, is the choice between Drop in or non-drop in products [25]. Coca-Cola's strategy aiming at a renewable packaging illustrates this dilemma. The company is funding both routes: a new plastic (PEF, a non-drop in material) and a 100\% renewable PET.

One of the other critical questions addressed by the innovators is which market to target (final or intermediary products, commodities or specialties, or a platform that really adds value to sugar). In this case, it is important to find a way to develop new applications for very innovative non-drop in products and organize a new chemical platform providing value creation along the production chain, while simultaneously building business models with value capture for the product innovator.

It is possible to identify some innovative initiatives in Brazil related to new technologies and products [26-28]. Second-generation ethanol in particular seems to be taking off with GranBio and Raizen's projects. Amyris' farnesene and Solazyme's algal oils, two very new technologies at the world level, are already being 
produced at commercial plants in São Paulo. In the bioplastics field, Braskem is a pioneer with its 200,000 tonnes per year green polyethylene plant, a drop in bioplastic based on ethanol. Ethanol conversion to ethylene, the polyethylene building block, is based on an old process updated and scaled up by Braskem.

\section{Business models and strategies}

The business models and strategies for first-generation ethanol and biodiesel are well known. However, considering innovative biofuels and biobased chemicals and polymers, the industry is still under construction. In the structuring spaces we have identified - raw materials, technologies, and products - a very diverse group of firms is competing. We can identify technology-based startups such as Genomatica, Solazyme, LanzaTech, Gevo, Amyris, Renmatix, Kior, and many others; firms from the chemical and petrochemical industries such as DuPont, DSM, BASF, Braskem, Dow, and Solvay; oil and gas companies such as Shell, BP, Petrobras, and Total; agribusiness companies such as ADM, Bunge, and Cargill; food ingredients companies such as Tate \& Lily, Roquette, and Purac; and paste and paper firms such as Stora Enso, UPM, Borregaard, and Fibria, not to mention venture capital investors [29].

These different firm profiles imply different key competencies with which companies try to enter the biobased industry. At the same time, there are complementary competencies that each firm has to access to achieve a competitive position in the industry. As a consequence, different business models have been tested. These different business models reflect the different ways to value the firm's key competencies and to associate in order to acquire the complementary competencies. Thus, even if the most innovative technologies have emerged from the technology-based startups, much of the complementary requirements - feedstock supply, scaling-up and production at a commercial scale, marketing and commercialization - are held by established companies. These companies - e.g., the chemical and petrochemical companies - have expertise and complementary assets needed to establish relations with the user industries (end users) and develop commercial applications. Moreover, the availability of resources and access to funding sources vary according to the different company profiles.

\section{Conclusions}

This paper has examined the biobased industry as an industry under construction. The dynamics of this industry is based on innovation and its competitive structure is still being shaped.

We have tried to highlight its complex innovation dynamics, showing that the selection environment presents multiple alternatives related to the four key dimensions, each of which has its own challenges and innovation processes, but also having mutual influence. Therefore, the future of this emerging industry depends on how these will evolve. The existence of government support and financing, as well as private funds, is an important external element affecting the industry's development.

The emergence of dominant designs and enabling technologies will constrain innovation, changing competition patterns and restricting the entrance of new players. From a strategic perspective, Brazil should use its comparative advantage to be well positioned in global competition. This requires government policies and incentives, private initiatives, and knowledge development, especially in new fields that seem to be crucial, such as synthetic biology. Research infrastructure and scaling-up skills should also be fields of intensive effort in order to advance Brazil's participation in this promising industry.

\section{Abbreviations}

BNDES: The Brazilian Development Bank; DD: dominant design; FINEP: Funding of Studies and Projects.

\section{Competing interests}

The authors declare that they have no competing interests.

\section{Authors' contributions}

JVB and FCA developed together the paper, from the concept to the final version, working together in every research step and writing. All authors read and approved the final manuscript.

\section{Author details}

${ }^{1}$ School of Chemistry/Institute of Economy/Universidade Federal do Rio de Janeiro (UFRJ), Technology Centre, Bloco E, room 209, Ilha do Fundão, Rio de Janeiro 21941-909, RJ, Brazil. ${ }^{2}$ School of Chemistry/Universidade Federal do Rio de Janeiro (UFRJ), Technology Centre, Bloco E, room 209, Itha do Fundão, Rio de Janeiro 21941-909, RJ, Brazil.

Received: 1 April 2014 Accepted: 30 September 2014

Published online: 29 October 2014

\section{References}

1. International Energy Agency. Technology roadmap, biofuels for transport. [http://www.iea.org/publications/freepublications/publication/ biofuels_roadmap.pdf]

2. Patel M, Crank M, Dornburg V, Hermann B, Roes L, Hüsing B Medium and long-term opportunities and risks of the biotechnological production of bulk chemicals from renewable resources - the BREW Project. [http://brew.geo.uu.nl/BREW_Final_Report_September_2006.pdf]

3. de Jong E, Higson A, Wellisch PW (2012) Product developments in the bio-based chemicals arena. Biofuels, Bioprod Bioref 6:606-624

4. Christensen C (1997) The innovator's dilemma. When new technologies cause great firms to fail. Harvard Business School Press, Boston, MA

5. Nelson R, Peterhansl A, Sampat B (2004) Why and how innovations get adopted: a tale of four models. Industrial and Corporate Change 13(5):679-699

6. Dosi G (1982) Technological paradigms and technological trajectories. Research Policy 11:147-162

7. Abernathy W, Utterback J (1978) Patterns of industrial innovation. Technology Review 80(7):41-47

8. Jacobsson S, Bergek A (2004) Transforming the energy sector: the evolution of technological systems in renewable energy technology. Industrial and Corporate Change 13(5):815-849

9. Teece D (2007) Explicating dynamic capabilities: the nature and microfoundations of (sustainable) enterprise performance. Strategic Management Journal 28:1319-1350

10. Von Hippel E (1988) The sources of innovation. Oxford 
11. Pavitt K (1984) Sectoral patterns of technological change: towards a taxonomy and a theory. Research Policy 13(6):343-373

12. Froling M, Schweinle J, Meyer J, Schultman F (2011) Logistics of renewable raw materials. In: Ulber R, Sell D, Hirth T (ed) Renewable raw materials: new feedstocks for the chemical industry. Wiley-VCH Verlag GmbH \& Co. KGaA, Weinheim, Germany

13. Spitz PH (1988) Petrochemicals: The rise of an industry. Wiley-Interscience, New York, $588 \mathrm{pp}$

14. Sims REH, Mabee W, Saddler JN, Taylor M (2010) An overview of second generation biofuel technologies. Bioresource Technology 101(6):1570-1580

15. Wright MM, Brown RC (2007) Comparative economics of biorefineries based on the biochemical and thermochemical platforms. Biofuels, Bioproducts and Biorefining 1(1):49-56

16. Nyko D, Valente MS, Milanez AY, Tanaka AKR, Rodrigues AVP (2013) A evolução das tecnologias agrícolas do setor sucroenergético: estagnaação passageira ou crise estrutural. BNDES Setorial 37:399-442

17. CGEE (2010) Química verde no Brasil: 2010-2030. Brasilia. http://www.cgee. org.br/busca/ConsultaProdutoNcomTopo.php?f=1\&idProduto $=6528$

18. BNDES, PAISS Agrícola. http://www.bndes.gov.br/SiteBNDES/bndes/ bndes_pt/Areas_de_Atuacao/Inovacao/paissagricola.html

19. Bozell JJ, Petersen GR (2010) Technology development for the production of biobased products from biorefinery carbohydrates - the US Department of Energy's "Top 10" revisited. Green Chemistry 12:539-554

20. BNDES, PAISS. http://www.bndes.gov.br/SiteBNDES/bndes/bndes_pt/ Areas_de_Atuacao/Inovacao/paiss/

21. Regalbuto JR (2011) The sea change in US biofuels' funding: from cellulosic ethanol to green gasoline. Biofuels, Bioproducts and Biorefining 5(5):495-504

22. World Economic Forum: the future of industrial biorefineries. http://www3. weforum.org/docs/WEF_FuturelndustrialBiorefineries_Report_2010.pdf

23. Hermann B, Carus M, Patel M, Blok K (2011) Current policies affecting the market penetration of biomaterials. Biofuels, Bioproducts and Biorefining 5:708-719

24. IEA Bioenergy Task 42, biobased chemicals. http://www.iea-bioenergy. task42-biorefineries.com/upload_mm/b/a/8/6d099772-d69d-46a3-bbf762378e37e1df_Biobased_Chemicals_Report_Total_IEABioenergyTask42.pdf

25. Oroski F, Alves FC, Bomtempo JV (2014) Bioplastics Tipping Point: drop-in or non-drop-in? Journal of Business Chemistry 11(1):43-49

26. Lane J Brazil's big six in advanced biofuels and chemicals: who's doing and what now? http://www.biofuelsdigest.com/bdigest/2013/09/16/brazils-bigsix-in-advanced-biofuels-chemicals-whos-doing-what-now/

27. International Energy Agency IEA (2013) World Energy Outlook 2013. OECD/ IEA. http://www.iea.org/Textbase/npsum/WEO2013SUM.pdf

28. BNDES, Brazilian Development Bank (2013). The BNDES and the sugarethanol industry in 2012: innovation as a priority. Sectoral Report. http:// www.bndes.gov.br/SiteBNDES/export/sites/default/bndes_pt/Galerias/Arquivos/conhecimento/setorial/Informe_25_ingles.pdf

29. Bomtempo JV, Alves FC, Oroski F (2014) Innovation strategies diversity in the biobased economy: a comparative approach. http://cit2014. sciencesconf.org/conference/cit2014/pages/bomtempo_alves_oroski_paper. pdf

doi:10.1186/s40538-014-0019-8

Cite this article as: Bomtempo and Alves: Innovation dynamics in the biobased industry. Chemical and Biological Technologies in Agriculture 2014 1:19.

\section{Submit your manuscript to a SpringerOpen ${ }^{\circ}$ journal and benefit from:}

- Convenient online submission

- Rigorous peer review

- Immediate publication on acceptance

- Open access: articles freely available online

- High visibility within the field

- Retaining the copyright to your article

Submit your next manuscript at $\gg$ springeropen.com 